eight feet $\mathrm{C}$ of musicians, the other, being an octave lower in pitch, adds an octave to the intervals obtained from the first fundamental ; thus, the third with the first fundamental becomes the tenth with the sub-fundamental. The horizontal box is furnished with a set of reeds giving all the intervals up to the twelfth, including the unison. The horizontal reeds are changed for the production of the different figures, the fundamental reed being retained.

A free space of half an inch was allowed between the supply pipe and the reed box, so as to afford a cushion of air capable of yielding to the elasticity of the tongue. The supply pipe is contracted at its termination to about one-third the size of the hole in the reed box through which the wind enters.

The apparatus is used as follows:- The base board being firmly clamped to a rigid table, one of the fundamental reeds is clamped in front of the box B : another reed, giving the desired interval, is similarly clamped to the box $\mathrm{B}$; an elastic tube, about half an inch in diameter, is attached at one end to the pipe $\mathrm{C}$, and at the other to an acoustic bellows. A fine pencil of light is now thrown on the mirror $\mathrm{E}$, which is then adjusted by rotation of the box $A$ until the light strikes the mirror of the vertical reed, from whence it is reflected on to a screen of tracing paper placed a short distance away; a condenser, interposed between the lantern and the mirror $\mathrm{E}$, focuses the spot of light on the screen. On the bellows being put in motion the figure appears, and can be brought to a perfect stand in any phase of development, looped or cusped, by careful manipulation of one or other of the cocks. The entire apparatus should be as rigid as possible, and free from any vibration other than that produced by the tongues of the reeds, and also that the wind supply should be perfectly steady.

\section{THE PARIS OBSERVATORY}

$A$ S we announced some time ago, an important step has been talen for the reormanisation of the Paris Observatory. A decree of the Presidcnt of the French Republic has appointed ten members of the new council of the Observatory, in pursuance of the provision:; of the organic decree we referred to two months avo. The principal object of this new institution being to connect the observatory with the several large French administrations, three Government departments have sent two delegates each. The War Office is represented by Col. Lausseclat, the clirector of the balloon service, and Commander Perrier, the chief of the Ordnance Survey; the Minister of Marine by two rear-admirals, one of them, M. Jurier de la Gravière, being a member of the late Council; the other is $\mathrm{M}$. Clonet; the department of agriculture by M. Tisserand, Director of the National School of Agriculture, and $M$. Hervé Mangon, a member of the Institute and presiclent of the Meteorological Society of France. The Academy of Sciences is represented by four members, carefully selecterl, viz., M. Dumas, the perpetual secretary, who is to be appointed presiclent, and M. Liouville, the celebrated geometer, and two astronomers, M. Faye and M. Mouchez, both of them members of the Section of Astronomy. It must be noted that the Council of the Observatory, although vested with the right to present to the minister two candiclates for the directorship of that cstablishment, are not to interfere with the solution of technical questions. A special council composed of all the astronomers on tilve of the Observatory, are to meet once a month to solve them with the director of the Observatory. The first meeting of the Council of the Observatory took place on A pril 24, M. Dumas being in the chair. The members had been summoned in order to send to the Ministry a list of two candidates for the direction rendered vacant by the demise of M. Leverrier. The meeting was very short, and the members having becn unable to agree, it was postponed to the 26 th, when M. Faye wished to cleliberate on the yexed question of the separation of metcorology and astronomy. This, however, was not allowed, when M. Faye protested and declared that he would bring the yuestion before the Academy of Sciences at its next meeting, on April 29. After several scrutinies the Council decided to send in the names of MM. Mouchez, Loewy, and Tisserand as their nominees for the directorship of the Observatory, the last two having obtained an equal number of votes. Such was the result of the deliberations of the Observatory Council, which on the whole seem to have been conducted with becoming dignity. At Monday's sitting of the Academy, M. Dumas simply read M. IBardonx's letter, and summoned a meeting for to-day of a Committee of the Academy composed of all the sections in the mathematical sciences. A list of candidates will then be formed for proposal to the whole Academy, which will vote its candidates on May 5. It then remains with the Government to choose between the candiclates proposed by the Council and Academy. $M$. Faye made no protest at the Academy meeting on Monday, though, our corresponclent writes, he was expected to speak on the subject in a secret committee which met after the meeting of the Academy. We trust that throughout these important steps for the appointment of a successor to Leverrier all personal feelings will be suppressed, and the interests of the Observatory and of science alone considered.

\section{SOCIETIES AND ACADEMIES \\ LONDON}

Royal Society, February 7.- "On the Diurnal Range of the Magnetic Declination as recorded at the Trevandrum Obser. vatory," by Balfour Stewart, LL.D., F.R.S., Professor of Natural Philosophy at Owens College, Manchester.

The Observatory at Trevandrum was supported by $\mathrm{His}$ Highness the Rajah of Travancore, and its director was Mr. J. A. Broun, F.R.S., who has recently published the first volume of the results of his labours, giving the individual observations of magnetic declination, and deducing from them conclusions of great scientific value.

Amongst the other results published by Mr. Broun, are the diumal ranges of the magnetic declination at Trevandrum for each civil day in the eleven years, I 854 to 1864.

In one respect the treatment of the declination observations at Trevandrum differs from that pursued at the Kew Observatory, inasmuch as in the former place, where disturbances are little felt, the diurnal ranges are from all the observations.

\section{Variations of Long Period.}

In order to investigate the long-period variation of the Trevandrum declination-range, I have treated these observations pre. cisely in the way in which the Kew declination-ranges were treated (Proc. Roy. Soc., March 22, I877). By this method proportional values of the declination-range at Trevandrum have been obtained corresponding to weekly points for each year, and it is believed that these values are freed from any recognised inequality deperding either on the month of the year or on the relative position of the sun and moon. If this method should be found to furnish nearly the same results in the case of two observatories so widely apart as Kew and Trevandrum, and with such marked differences in the annual variation of the declination-range, we may conclude that this separation of inequalities has been successfully accomplished.

The proportional numbers have next been dealt with precisely in the way in which the corresponding numbers were dealt with in the case of the Kew Observatory, that is to say, a set of nine. monthly values of declination-range have been obtained corresponding to similar nine-monthly values of spotted solar area.

The results of this treatment are exhibited in the diagram which accompanies this paper.

In Fig. I we have a curve representing the nine-monthly values of spntted area.

In Fig. 2 we have the Kew and in Fig. 3 the Trevandrum declination curve represented by nine-monthly values of the propurtional numbers.

In Fig. 4 we have a curve representing the mean between the proportional numbers of Kew and those of Trevandrum.

From these figures it will be seen that a lagging behind the sun is a feature both of the Kew and the Trevandrum curves, while generally the prominent points in the Kew and Trevandrum curves agree well together in point of time.

On the whole it would appear that by taking the mean of the proportional numbers for the two stations, we get a curve that represents the solar curve better than one derived from a single station.

The whole period compared together represents both foc the solar curve (Fig. I) and the mean curve (Fig. 4), a series of three smaller periods, one extending from $\mathrm{B}$ to $\mathrm{C}$ and embracing the maximum; another extending from $\mathrm{C}$ to $c$, and a third from $c$ to $e$; and this is as far as the observations common to both stations allow us to go in point of time.

It may be of interest to compare, by means of the tables, the period between the solar minimum of 1855 and that of 1867 , with the period between the corresponding declination-range minima. The first of these declination minima occurred at Trevandrum (the 
Kew observations not having then begun) on February 15,1856 , and the second of them occurred at Kew (the Trevandrum ob. servations having been discontinued) on August 15, 1867. The period is thus one of eleven years and six months.

On the other hand, the sun-spot period is that between September 15, 1855, and March 15, 1867, being likewise eleven years and six months.

d. Variations which seem to depend on Planetary Configurations.

In a paper on the Kew declination-range already alluded to, it was shown that the planetary periods of most frequent occur- rence appear to be well indicated by the results of sixteen years observations. Indeed, for the two periods of shortest lengththat of Mercury about the sun, and that of Mercury and Jupiter, it was found that half of the observations gave a result of the same character as the whole sixteen years.

From this we might conclude that these periods will probably (if they have a real existence) be indicated by the Trevandrum observations.

It will be seen from the following tables that the Trevandrum declination-ranges give results for these two planetary periods very similar to those given by the $\mathrm{Kew}$ observations.

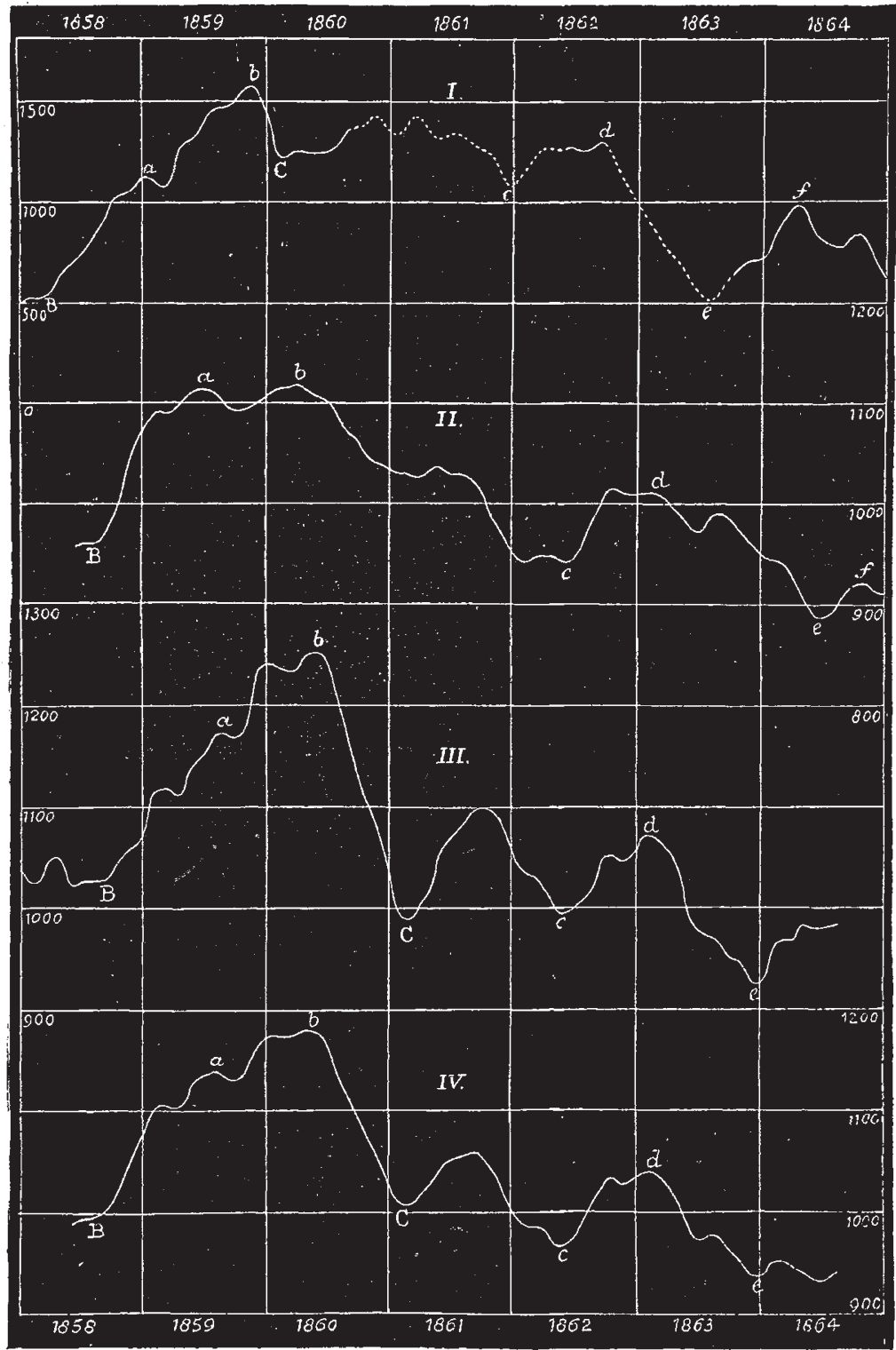

Period of Mcrcury about the Sun.

( $0^{\circ}$ denoting Perihelion -65 sets for Kew -47 for Trevandrum.)

\begin{tabular}{|c|c|c|c|c|c|}
\hline Between & ${ }^{\circ} 0$ & and & $\begin{array}{l}\text { o } \\
\text { 30 }\end{array}$ & $\begin{array}{l}\text { Kew. } \\
+429\end{array}$ & $\begin{array}{c}\text { Trevandrum. } \\
+263\end{array}$ \\
\hline 然 & 30 & " & 60 & +433 & +223 \\
\hline ", & 60 & " & 90 & +256 & +237 \\
\hline$"$ & 90 & is & 120 & & +300 \\
\hline " & 120 & , & 150 & -280 & +150 \\
\hline
\end{tabular}

$\begin{array}{cccc}\text { Between } & \text { I } 50 & \text { and } & \text { I80 } \\ , " & 180 & , & 210 \\ ", & 210 & , & 240 \\ " & 240 & , & 270 \\ " & 270 & , & 300 \\ " & 300 & , & 330 \\ , & 330 & , & 360\end{array}$

Kew.

$-439$

$-413$

$-279$

$-140$

+13
+158
+1278

$+278$
Trevandrum.

$-433$

$-879$

$-740$

$-263$

$+333$

$+680$

$+506$ 
Period of Conjunction of Mercury and Fupitir.

$10^{\circ}$ denoting Conjunction-63 sets for $\mathrm{Kew}-43$ sets for Trevandrum.)

\begin{tabular}{|c|c|c|c|c|c|}
\hline Between & $\stackrel{\circ}{\circ}$ & and & $3^{\circ}$ & $\begin{array}{l}\text { Kew. } \\
+633\end{array}$ & $\begin{array}{l}\text { Trevandrum. } \\
+453\end{array}$ \\
\hline 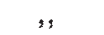 & 30 & I & 60 & +759 & +270 \\
\hline , & 60 & , & 90 & +652 & +129 \\
\hline , & 90 &, & 120 & +328 & -118 \\
\hline$:$ & 120 & $"$ & 150 & $-1 \times 9$ & -384 \\
\hline , & 150 &, & 180 & -504 & -467 \\
\hline , , & 180 &, & 210 & -678 & -487 \\
\hline, & 210 & , & 240 & -677 & -407 \\
\hline , & 240 & , & 270 & -548 & -122 \\
\hline ", & 270 & , & 300 & -322 & +223 \\
\hline , & 300 & , & 330 & -10 & +415 \\
\hline , & 330 & ", & 360 & +343 & +503 \\
\hline
\end{tabular}

Zoological Society, April 16.-E. W. H. Holdsworth, F.Z.S., in the chair.-Mr. Sclater exhibited and made remarks on a typical specimen of the new fox lately described by $\mathrm{Mr}$. Blanford as Vulpes canus, from Baluchistan.-.The Secretary exhibited, on behalf of Mr. A. Anderson, F.Z.S., a bamboo stick with leather thong attached to it, such as is used in India for driving plough-cattle with, which had been talien out of a nest of the common Fish Eagle (Haliaetus leucoryphus), in December, 1876.-Prof. Westwood communicated a memoir on the Uraniidee, a family of lepidopterous insects, with a synopsis of the family and a monograph of one of the genera, Coronidia. These insects were remarkable for their extreme beauty and the difficulty which had attended their systematic classification. Their relations with other groups of lepidopterous insects were discussed at considerable length, and their nearest affinities were shown to be with certain other moths belonging to the great division of the Bombyces, whilst their connection with the Hesperian butterfies, the Psendo-sphinges, Erebidcous Noctx and Ourapterygeous Geometre was disproved by their general structure, the venation of their wings and their transformations. A synopsis of the species of all the genera was given, and a complete monograph with figures of the genus Coronidia. -Mi. Gwyn Jeffieys, F.R.S., F.Z.S., read the first part of his work on the Mollusca, procured in the expeclitions of H.M. S.S. Lightning and Porcupine. It would be recollected that these expeditions immediately preceded that of I-I.M.S. Challenger, but were restricted to portions of the North Atlantic, including the Mediterranean. The Brachiopods formed the subject of the present paper. A table of all the Brachiopods known to inhabit the European seas was given, comprising ten genera and twenty-two species, of which latter four were for the first time lescribed and six figured. The table also particularised the geological and hathymetrical range of all the species. Two plates accompanied the paper, and were furnished by Mr. Davidson.-Mr. G. E. Loder, F.Z.S., exhibited and made remarks on a mounted heack of the Rocky Mountain Bison, remarkable for its soft, clark, and long hair on the forehead. This specimen had been oltained near Denver, Colorado. - A communication was reac from the Marquis of Tweeddale, F.R.S., containing the eighth of his contributions to the ornithology of the Philippines. The present paper gave an account of some Luzon birds in the Museum at Darmstadt, which had been sent to him for examination by Prof. Koch of that place. -A communication was read from Dr. O. Finsch, C.M.Z.S., containing description of a new species of finch from the Feejee Islands, which he proposed to name Amblynura kleinschmidti after Mr. Kleinschmidt, by whom it had been found in the interior of Viti. Levu, -. Dr. M. WVatson reat a priper containing a clescription of the generative organs of the male spotted hyana (Hyana crocuta), and a detailed com marison of them with those of the female of the same animal. Messrs. Sclater and Salvin read a report on the collection of birds made cluring the voyage of H.M.S. Challenger at the Island of Juan Fernandez, at various points along the coast of Tatagonia, and at the Falkland Islands.-A second paper by Messrs. Sclater and Salvin gave descriptions of three new species of birds from Ecuador, proprosed to be called Buarremon lucopis, Neomorphus radiolosus, and Aramides calopterus.

$$
\text { Wellington, N.Z. }
$$

Philosophical Society, August 18, 1877.-After the confirmation of the previous meeting's minutes, and the announcement of $\mathrm{Mr}, \mathrm{B}$. T. Chaytor and Mr. Robert Govett as newly elected members, the President (Mr. W. T. L. Travers, F.L.S.,
M.H.R.), read his paper on remarks as to the cause of the warmer climate which exister in high northern latitudes during former geological periods. This paper was a review of the progress recently made in our knowledge of the subject, and especially the bearing of Naysmith and Carpenter's examination of the moon's surface, and the work by. Mr. Mathieu Williams on the "Fuel of the Sun." The author adopted the view that the gradual condensation of water on the earth's surface, consequent on the loss of its original cosmical heat, had produced the succession of phenomena resulting in the present distribution of life ; that in consequence of the cooling having taken place first in the polar regions, it was there that the higher and latestformed organisms must have first appeared. He adduced as proof of this the existence of fossilised vegetation within the Arctic regions which had almost a tropical character, and other evidence that during successive geological epochs the changing character of the fauna and flora in other regions showed that the climate had gradually become more and more temperate. $\mathrm{Dr}$. Hector would only speak as regards the geological aspect of the author's paper. The fact that the oldest rocks we know are either hydrated or formed by the action of water as sediments proved that our geological records did not carry us back to a time when very high temperature prevailed. It was only, therefore, necessary to inquire into the evidence of a minute secular cooling afforded by the succession and distribution of animals and plants during former epochs. He considered this evidence very unsatisfactory, and not leading in the direction the author required. The former existence of temperate plants in high latitudes took place at a very late period in the earth's history, and long after some temperate regions had possessed a fauna and flora similar to that at the present time. There had, in fact, been several repetitions of the abnormal distribution of animals and plants on which the author founded his argument, and consequently of the climate; so that these changes could hardly be referred to the progressive cooling of the globe as a whole. The inferences made had chiefly been drawn from late tertiary strata, but in the case of New Zealand there was evidence that the same type of vegetation had surviver since the early part of the cretaceous era, a period twenty times as great as that which had elapsed since the supposed sub-tropical fauna inhabited Central Europe, or the temperate flora flourished in the Arctic regions. From this it was surely to be argued that the cause had not been one of universal operation. Concerning the former Arctic flora the real difficulty was not the question of temperature so much as the absence of light in that region for six months of the year if all other conditions of the earth remained as at present, except a general higher surface temperature. Many SFeculations had been put forward on this subject; one of the latest, by John Evans, was that the earth was solid with an oxydised crust, separated from the central nucleus by a viscous layer of unequal thickness in which chemical combination, or, as it may be called, the "rusting process," was still active. The elevation of mountain masses by the fracture of the crust would act like weights on a gyroscope and lead to a gradual displacement of the outer crust with reference to the axis of rotation of the interior bulk of the earth, which astronomers required us to believe to be immovable. He also pointed to recent researches of Prof. Duncan regarding reef-building corals, which at the present time are confined to a narrow equatorial belt, but in eocene times that belt appears to have had a distribution oblique to the present equator. If this were established it would offer a still greater difficulty in the way of accepting the view that the changes in distribution of climate were due to the secular cooling of the earth as a prime cause. Mr. Carruthers thought it not yet proved that there was a central heat, and certainly not that it could influence climate. He thought the balance of evidence was against the theory of central heat. If the earth had once been hotter it would have become smaller in cooling, and its velocity of rotation would have increased; but this was contrary to fact, as the rotation had been retarded by about three hours since exact observations were first made. With regard to what had been said about the thickness of the earth's crust, the existence of tides proved that it must be so great as to be absolutely rigid. He considered it quite possible for plants to live in darkness if they remained dormant, like geraniums, which are placed in a dark cellar during the winter.

September I, 1877. - Mr. W. T. L. Travers, president, in the chair.-Mr. Coleman Phillips read his paper on a peculiar method of arrow propulsion as observed by the Maoris. The author gave an interesting description of how 
the arrows were thrown by means of a string, which he illustrated before the meeting with a model, He expressed surprise that, as far as he was aware, nothing was known of the bow among the Maoris, a weapon so commonly used by natives of other islands. Mr. Grace, who had been in New Zealand from his youth, said that the bow and arrow was a common weapon in the interior with the Maori youths, and he believed that it was originally used by the natives. It was, however, found by them to be an inconvenient weapon in the bush, and hence their reason for adopting the plan mentioned by $\mathrm{Mr}$. Phillips. The Maori scarcely ever threw a spear by hand; they used the string twisted round a fork in the spear. The notch mertioned by the author was new to him.-The President read a paper on grasses and fodder plants by Dr. Curl, being a continuation of a paper by the same author read last year, and printed in vol. ix. of the Transactions. - Mr. Carruthers read a paper on a system of weights and measures, in which it was proposed to change the radix of counting from 10 to 16 , and to adopt the latter number as the radix for all weights and measures.

\section{Philadel.phia}

Academy of Natural Sciences, November 13.-The agricultural ants of Texas, by Rev. H. C. McCook.-On a stone axe, by Mr. J. Ford. This was found in a bluff fifty feet above the level of the Mississippi, and embedded twenty feet deep in solid limestone, without. fissure or crevice, giving evidence of great age.

November 27.-Remarks on American species of Diffugia, by Prof. Leidy. - On the aëronautic flight of spiders, by Rev. H, C. McCook.

\section{VIENNA}

Imperial Academy of Sciences, February 7.-_"Mono. graphia Pulmonariarum," by M. Kerner.-On bixin, by $M$. Etti. - A centrifugal air-ship, by MM. Szigyarto and Kuczera.-On the originals of v. Born's Testaceis Musei Cæesarei Vindo. bonensis ( 1780 ), found in the Imperial Zoological Museum, by M. Braiser.-On new neuroptera, by $M$. Steindachner. -On a peculiar spinal cord band in some reptilia and amphibia, by M. Berger.

February 14. - Construction of tangents at the contact line of a rotation surface and the developables described outwards and round it from a point, by M. Drasch. -Completing additions to the general mode of determination of the focus of contours of surfaces of the second degree, by $M$. Peiz. - On the action of bromine on phenoldisulphoacid, by M. Schmidt.-On the products of decomposition of a gum-ammoniac of Morocco by melting hydrate of potash, by Dr. Goldschmidt. - Telephone signalling apparatus, by $M$. Puluj.

\section{ROME}

$\mathrm{R}$ Accademia dei Lincei, February 3-New researches on the ossiferous caves of Liguria, by MM. Gasteldi and Ferroti. - Discovery of arms of stone and bronze in Calabria, by M. Ruggeri.-Geological and palrontological studies on the middle cretaceus of Southern Italy, by M. Seguenza.-On benzylic santonate, and on tribenzylamine and its chloroplatinate, chlorhydrate, sulphate, alum, and nitrate, by M. Panebianco.On the new anomalous anastomosis between the trochlean nerve, the supra-orbital and the sympathica cavemosa, by M. Berté.Now general the orem of mechanics, by M. Cerruti.

\section{PARIS}

Academy of Sciences, April 22.-M. Fizeau in the chair.The following among other papers were read:-Researches relative to the action of dry oxalic acid on primary, secondary, and tertiary alcohols, by MM. Cahours and Demarçay. This is in completion of a former study (C. R. vol. Ixxxiii. p. 688). The experiments were made with methylic alcohol, primary and secondary octylic alcohol, trimethyl-carbinol, and dimethyl ethyl-carbinol. The action of dry oxalic acid on tertiary alcohols, which consists in splitting them into hydrocarbons and water which unites with the acid, establishes a very marked distinction between them and primary and secondary alcohols, which, in like circumstances, are transformed always into oxalates. - Report on a memoir by Lieut. Pinheiro of the Brazilian navy, oll a sondograph. This instrument is for giving information rezarding banks in rivers. A wooden rod is fitted at its lower end with a hollow roller to roll on the bottom and collect small portions of the material; at the top it is articulated round a horizontal axis carrying a graduated arc (which shows the various inclinations) and also a toothed wheel, which, though a pinion and eccentric, gives a straight motion to a style, tracing a continuous curve on a moving band of paper.-M. Gaiffe exhibited a manometric safety steelyard. It is mounted on steel pivots, and connected with a piston having ten square millimetres of surface. It indlicates with precision the presstre of the boiler. Annexed is an slarm whistle communicating with a valve box by a graduated rod.A letter from M. André was read, announcing the arrival at Ogden, Utah, of the party sent out to observe the transit of Mercury, The U.S. Government had given them the use of the nearly finished observatory at Ogden, and any instruments they wished; the photographic instruments used by the Ameri. can Venus transit expedition were put in their hands. A telegraph wire connects Ogden with Washington.-Observations of solar spots and protuberances during the first quarter of 1878 , by $M$. Tacchini. The number of spots has continuously diminished since the beginning of last year, so that the minimum appears to fall, not in 1877 , but in 1878 . The protuberances, too, have been very few and small : $2 \cdot x$ on an average daily, with a height of half a mintute; they occupy only $3.5^{\circ}$ of the solar limb. In distribution they extend over a large zone, but with the peculiarity of two characteristic maxima beyond the principal zones of spots, i.e. between $30^{\circ}$ and $60^{\circ}$ in both hemispheres. The nebulous structure predominated. There were no isolated metallic eruptions.-On observations of Mercury, made at the end of last century, by Vidal at Mirepoix, by $M$. Bigourdan. These are shown to be as accurate as was possible with the means at Vidal's disposal.-Results of experiments made at various points of Algeria, in industrial use of solar heat, by M. Mouchot. The reflectors he finds best are made. of a plate of silver, or brass electro-plated with a thin layer of silver. At Algiers the heat received per minute by his solar boiler was 7 calories in April, 8 in May, and 8.5 in June and July. M. Mouchot tabulates the results obtained in various localities; they range from 9.8 cal. to 5 .- On a large fossil reptile (Eury'sazinus raincourti), by M. Gaudry. The remzins of this were come upon by workmen in a quarry near Vesoul, as far back as I86I. A Dr. Gevrey happened to pass and brought some of the blocks of bone to Vesoul, where they have been forgotten seventeen years. The Marquis de Rain. court having seen them perceived their interesting nature. The remains are estimated to have covered a space five metres in length. 'The animal has affinities to the plesiosaurians, but it is not a true plesiosaurus, for its head is so heavy and its teeth are so large that it could not have had a very long neck. The cervical vertebra, too, are narrower and convex behind. The cranim was flattened and the teeth were directed outwards. The nostrils must have been placed far back.

\section{CONTENTS}

PAGE.

Retrospect and Prospect. By the Edito

The American Stora Warnings. By Jerome j. Colims

Newcomis's Astronomy. By J.R. Hind, F.R.S.

Slate And Slate Quarkying

UR BOOK SHELF :-

Hulme's "Familiar Wild Flowers"

Geographical Books

LETTERS TO THE EDITOR:

The Telephone.-George S. Clirke; Herbert McLeod

Poisonous Australian Lake.-George Francis

Transmission of Vocal and other Sounds by Wires. - iv. ${ }^{\circ}$, Millar, C. $\mathrm{E}$

Westinghouse Brake.- $\mathrm{R}$

The Oxford Commissioners' Statement.-B.

Contact Electricity. $-J$. Brown

Solar Halo. - E. Rodie

Floating Magnets. By Sir Williak Thom F Illustrations)

A Rotaring Book-CASE (With lllustration)

Faustinus Jovita Marianus Malagut

Dr. Thomas Thomson, F.R.S. By Rev, M. J Berkei

The GReEnland Eskrmo. By A Borditr (With Illustrationts)

Pozzolana MTORTAR AND Pine Timper

Stanford's STEREOGRAPHICAL MAP OF THE British ISLE:

Our Astronomical Coluin:-

Transits of Mercury

Kepler's Manuscripts and Relic

The Pulkowa Library Catalogue

Geographicat Notes:-

Round the World

Africa

The Untversity OF OXFord Comisission

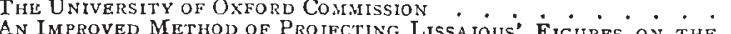

SCREEN. By J. DIXON MANE

SCREEN. By J. DIXON MANN, L.K.Q.C.P. (With Illustration). . 24

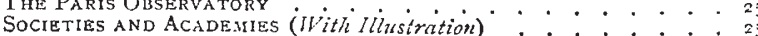

